\title{
Crystal structure of $\left[\left\{\left(\mathrm{Ph}_{3} \mathrm{Sn}\right)_{2} \mathrm{SeO}_{4}\right\} \cdot \mathrm{CH}_{3} \mathrm{OH}\right]_{n}$
}

4

Waly Diallo, ${ }^{\mathrm{a} *}$ Hélène Cattey, ${ }^{\mathrm{b}}$ and Laurent Plasseraud ${ }^{\mathrm{b} *}$

aLaboratoire de Chimie Minérale et Analytique, Département de Chimie, Faculté des Sciences et Techniques, Université Cheikh Anta Diop, DAKAR, Senegal ' ICMUB UMR CNRS 6302, Université de Bourgogne Franche-Comté, Faculté des Sciences Mirande, 9 avenue Alain Savary, F-21000 DIJON, France
*Corresponding authors

E-mails: diallo_waly@yahoo.fr (W. Diallo), laurent.plasseraud@u-bourgogne.fr

(L. Plasseraud)

\footnotetext{
Abstract: Crystallization of $\left[\left(\mathrm{Ph}_{3} \mathrm{Sn}\right)_{2} \mathrm{SeO}_{4}\right] \cdot 1.5 \mathrm{H}_{2} \mathrm{O}$ in methanol leads to the formation of $\left[\left\{\left(\mathrm{Ph}_{3} \mathrm{Sn}\right)_{2} \mathrm{SeO}_{4}\right\} \cdot \mathrm{CH}_{3} \mathrm{OH}\right]_{n}$ (1) which constitutes a new specimen of organotin(IV) selenate derivatives. In the solid state, complex $\mathbf{1}$ is arranged in polymeric zig-zag chains, composed of alternating $\mathrm{Ph}_{3} \mathrm{Sn}$ and $\mathrm{SeO}_{4}$ groups. In addition, pendant $\mathrm{Ph}_{3} \mathrm{Sn} \cdot \mathrm{CH}_{3} \mathrm{OH}$ moieties are branched along chains according to a syndiotactic organization and via $\mathrm{Sn}-\mathrm{O}-\mathrm{Se}$ connections. From a supramolecular point of view, intermolecular hydrogen bonds established between the selenate groups (uncoordinated oxygen) and the hydroxyl functions $\left(\mathrm{CH}_{3} \mathrm{OH}\right)$ of the pendant groups link the chains together.
} 
Keywords: organotin(IV), selenium, Sn-O-Se moiety, crystal structure, inorganic chain.

27

40

An inventory of crystallographic structures of organotin complexes exhibiting $\mathrm{Sn}-\mathrm{O}-\mathrm{Se}$ moieties was recently reviewed, highlighting the existence of a great diversity of compounds involving selenite, selenate and organoseleninate derivatives (Plasseraud, 2018). Based on bridging $\mathrm{SeO}_{4}{ }^{2-}$ groups, the class of organotin(IV) selenate exhibits the predominance of polymeric structures, involving in particular inorganic chains, with tin atoms exhibiting trigonal bipyramidal geometries. Recently, we completed this category by characterizing a new trimethyltin(IV) selenate specimen, $\left[\left(\mathrm{Me}_{3} \mathrm{Sn}\right)_{3}\left(\mathrm{SeO}_{4}\right)(\mathrm{OH})\right]_{n}$, isolated from the reaction of [( $\left.\left.\mathrm{Me}_{2} \mathrm{NH}_{2}\right)_{2} \mathrm{SeO}_{4}\right]$ and $\mathrm{Me}_{3} \mathrm{SnCl}$ in methanol (Diallo et al., 2018). Continuing our investigation in this field, we report herein the crystal structure of $\left[\left\{\left(\mathrm{Ph}_{3} \mathrm{Sn}\right)_{2} \mathrm{SeO}_{4}\right\} \cdot \mathrm{CH}_{3} \mathrm{OH}\right]_{n}(\mathbf{1})$ resulting from the crystallization of $\left[\left(\mathrm{Ph}_{3} \mathrm{Sn}\right)_{2} \mathrm{SeO}_{4}\right] \cdot 1.5 \mathrm{H}_{2} \mathrm{O}$ in methanol. An X-ray diffraction study from a suitable single crystal revealed, in the solid state, an organization based on polymeric zig-zag chains with pendant $\mathrm{Ph}_{3} \mathrm{Sn} \cdot \mathrm{CH}_{3} \mathrm{OH}$ groups (Scheme 1).

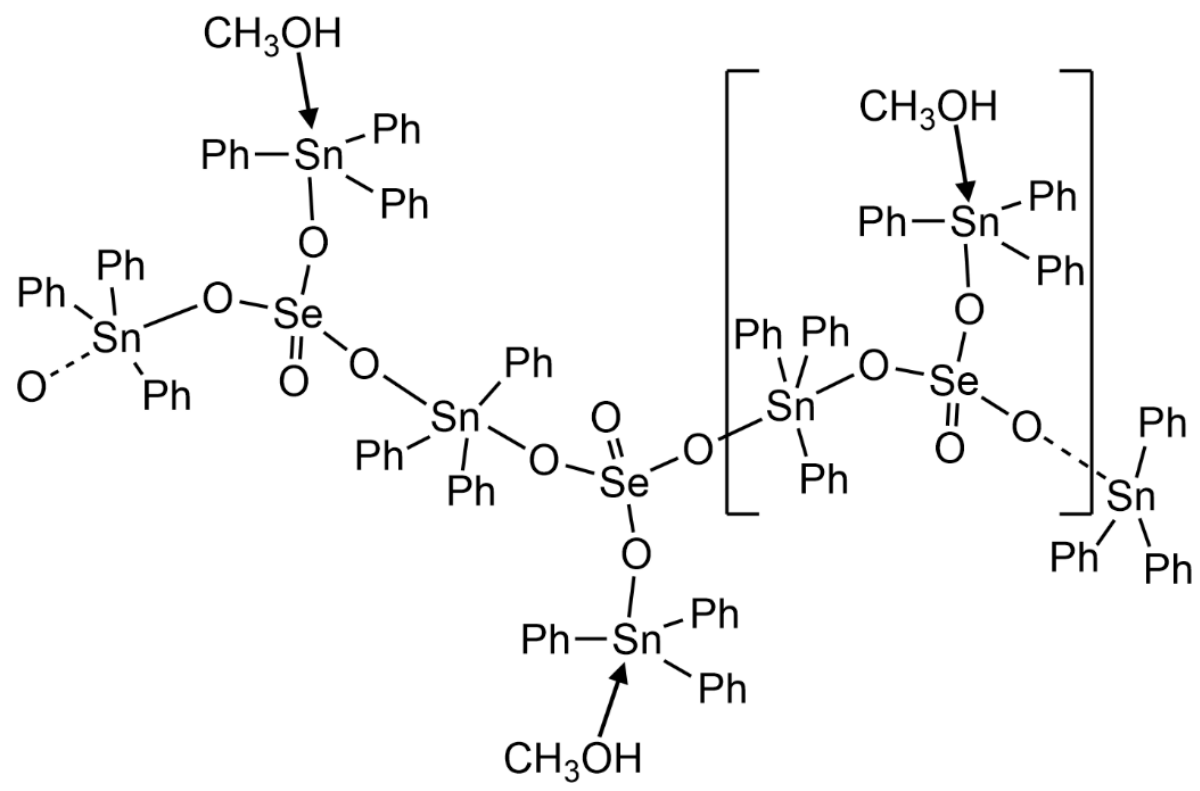


Scheme 1. Molecular representation of $\mathbf{1}\left(\mathrm{Ph}=\mathrm{C}_{6} \mathrm{H}_{5}\right)$ showing its zig-zag chain arrangement.

In the past, some of us reported the synthesis and the characterization of $\left[\left(\mathrm{Ph}_{3} \mathrm{Sn}\right)_{2} \mathrm{SeO}_{4}\right] \cdot 1.5 \mathrm{H}_{2} \mathrm{O}$ which was prepared from $\mathrm{H}_{2} \mathrm{SeO}_{4}$ and triphenyltin hydroxide in ethanol (Diop et al., 2007). The recrystallization of $\left[\left(\mathrm{Ph}_{3} \mathrm{Sn}\right)_{2} \mathrm{SeO}_{4}\right] \cdot 1.5 \mathrm{H}_{2} \mathrm{O}$ in methanol causes the displacement of $\mathrm{H}_{2} \mathrm{O}$ and leads to the growth of colorless prism-shaped crystals characterized as the new triphenyltin(IV) selenate, $\left[\left\{\left(\mathrm{Ph}_{3} \mathrm{Sn}\right)_{2} \mathrm{SeO}_{4}\right\} \cdot \mathrm{CH}_{3} \mathrm{OH}\right]_{n}(\mathbf{1})$. The crystal structure of $\mathbf{1}$ was resolved by the X-ray diffraction. Selected crystallographic data and refinement details are reported in Table 1. An OLEX2 view with selected bond lengths and angles $\left[\AA{ }^{\circ}{ }^{\circ}\right]$ is shown in Figure 1. The asymmetric unit of $\mathbf{1}$ contains two distinct tin(IV) atoms, each bearing three coplanar phenyl groups $[\mathrm{Sn} 1-\mathrm{C} 13=2.119(4), \mathrm{Sn} 1-\mathrm{C} 1=2.119(4), \mathrm{Sn} 1-\mathrm{C} 7=2.123(4)$, Sn2-C26 = 2.119(4), Sn2-C32 = 2.130(4), and Sn2-C20 = 2.122(4) Å. The two Sn atoms are trans-coordinated by two oxygen atoms and adopt a trigonal bipyramidal geometry (TBP). Values of $\mathrm{O}-\mathrm{Sn}-\mathrm{O}$ angles are almost linear $\left[\mathrm{O} 2-\mathrm{Sn} 1-\mathrm{O} 1=178.55(10)\right.$ and $\mathrm{O} 5-\mathrm{Sn} 2-\mathrm{O} 4^{\mathrm{i}}=$ 176.48(9) ${ }^{\circ}$. The structural indexes $\tau$ values of the Addison parameter (Addison et al., 1984) determined for $\mathrm{Sn} 1$ and $\mathrm{Sn} 2$ (0.950 and 0.919, respectively) indicate a distorted character for each TBP, which is consistent with earlier reports (Parvez et al., 2000). The apical positions of $\mathrm{Sn} 2$ are occupied by two oxygen atoms of two distinct tetrahedral selenate groups acting as tridentate and triply bridging ligand $\left[\mathrm{O} 5-\mathrm{Sn} 2=2.230(2)\right.$ and $\left.\mathrm{O} 4^{\mathrm{i}}-\mathrm{Sn} 2=2.285(2) \AA\right]$. For $\mathrm{Sn} 1$, one apical position is occupied by one oxygen atom of $\mathrm{SeO}_{4}{ }^{2-}[\mathrm{Sn} 1-\mathrm{O} 2=2.213(3) \AA]$, and the second by the oxygen atom of a coordinated $\mathrm{CH}_{3} \mathrm{OH}$ molecule $[\mathrm{Sn} 1-\mathrm{O} 1=2.320(3) \AA$ ] . The $\mathrm{Sn}-\mathrm{O}(\mathrm{Se})$ distances of $\mathbf{1}$ are in the range of those already reported for triphenyltin(IV) selenates [2.15-2.31 $\mathrm{A}]$ (Plasseraud, 2018). Regarding the $\mathrm{Ph}_{3} \mathrm{Sn}-\mathrm{O}(\mathrm{H}) \mathrm{CH}_{3}$ distance $[\mathrm{Sn} 1-\mathrm{O} 1=2.320(3)$ $\AA$ ], a comparable value was recorded for $\left[\left(\mathrm{Ph}_{3} \mathrm{Sn}\right)_{2} \mathrm{CrO}_{4}\right] \cdot \mathrm{CH}_{3} \mathrm{OH}[2.361(3) \AA]$ which is structurally similar to $\mathbf{1}$. [( $\left.\left.\mathrm{Ph}{ }_{3} \mathrm{Sn}\right)_{2} \mathrm{CrO}_{4}\right] \cdot \mathrm{CH}_{3} \mathrm{OH}$ was previously characterized as polymer 
chains resulting from the association of $\mathrm{Ph}_{3} \mathrm{Sn}$ moieties linked to tridentate $\mathrm{CrO}_{4}$ groups, and bearing also pendant $\mathrm{Ph}_{3} \mathrm{Sn}-\mathrm{O}(\mathrm{H}) \mathrm{CH}_{3}$ units (Diallo et al., 2007).

In the crystal lattice, $\left[\left\{(\mathrm{Ph} 3 \mathrm{Sn})_{2} \mathrm{SeO}_{4}\right\} \cdot \mathrm{CH}_{3} \mathrm{OH}\right]_{n}(\mathbf{1})$ is organized in infinite zig-zag chains, propagating along the $a$-axis and whose structure is based on alternating $\mathrm{Ph}_{3} \mathrm{Sn}^{+}$and $\mathrm{SeO}_{4}{ }^{2-}$ building-blocks (Figure 2). In addition, non-coordinated oxygen atoms of selenate anions are involved in intermolecular hydrogen bonding interactions with hydroxyl groups of methanol molecule of neighboring chains $[\mathrm{O} \cdots \mathrm{H}-\mathrm{O}=2.663 \AA]$. This results in the propagation of a grid-shaped three-dimensional network depicted in Figure 3.

Infrared spectroscopy analysis of $\mathbf{1}$ mainly shows the absorption bands corresponding to $v \mathrm{SeO}_{4}$ at 818, 727, and $693 \mathrm{~cm}^{-1}$ (Baran et al., 1997; Soukrata et al., 2014; Ben Hassen et al., 2014). In solution, despite the difficulties of solubilization in usual solvents, we were able to obtain the ${ }^{119} \mathrm{Sn}$ NMR fingerprint of $\mathbf{1}$ in $\mathrm{CD}_{3} \mathrm{OD}$ showing two broad resonances at $\delta-193.6$ and $\delta-215.1 \mathrm{ppm}$. The synthetic precursor, $\left[\left(\mathrm{Ph}_{3} \mathrm{Sn}\right)_{2} \mathrm{SeO}_{4}\right] \cdot 1.5 \mathrm{H}_{2} \mathrm{O}$, exhibited only one resonance at $\delta-213.0 \mathrm{ppm}$ (Diop et al., 2017). These values of chemical shift, are consistent with five-coordinated tin(IV) atoms in a trans trigonal bipyramidal geometry environment (Holeček et al., 1983) and support for $\mathbf{1}$ the preservation of the structure in solution. For comparison, the chromato structural analogue of $1,\left[\left(\mathrm{Ph}_{3} \mathrm{Sn}\right)_{2} \mathrm{CrO}_{4}\right] \cdot \mathrm{CH}_{3} \mathrm{OH}$, exhibits in $\mathrm{CDCl}_{3}$ only one resonance at $\delta-44 \mathrm{pm}$, which was explained by the disruption of the polymeric chains and reflecting the four-coordination environment of tin atoms in solution (Diallo et al., 2007). Regarding the ${ }^{13} \mathrm{C}\left\{{ }^{1} \mathrm{H}\right\}$ NMR spectrum of $\mathbf{1}$, carbon atoms of the phenyl groups exhibit chemical shifts comparable to $\left[\left(\mathrm{Ph}_{3} \mathrm{Sn}\right)_{2} \mathrm{SeO}_{4}\right] \cdot 1.5 \mathrm{H}_{2} \mathrm{O}$ (Diop et al., 2007), however the resonance corresponding to the ipso carbon is not visible. 
91 of triorganotin(IV) selenate and thus extends this class of compounds predisposed to lead to the

92 development of inorganic polymer networks.

93

94

95

96

Table 1. Crystal data and structure refinement of $\mathbf{1}$.

Formula

$\mathrm{C}_{37} \mathrm{H}_{34} \mathrm{O}_{5} \mathrm{SeSn}_{2}$

97 Formula weight, $\mathrm{g} \cdot \mathrm{mol}^{-1}$

874.98

98

Crystal system

Orthorhombic

$99 \quad$ Space group

$P 212121$

100

a, $\AA$

12.6189(3) $\AA$

$101 b, \AA$

15.4979(4) $\AA$

$102 c, \AA$

17.1412(4) $\AA$

$103 \alpha,{ }^{\circ}$

90

$104 \beta,^{\circ}$

90

$105 \beta,^{\circ}$

90

$106 V, \AA^{3}$

3352.24(14)

$107 \quad Z$

4

$108 \rho$ calcd, $\mathrm{g} \cdot \mathrm{cm}^{-3}$

1.734

$109 \mathrm{~T}, \mathrm{~K}$

115

$110 \mu($ Mo K $\alpha), \mathrm{mm}^{-1}$

$2.618 \mathrm{~mm}^{-1}$

$111 \quad F(000)$

1720

112

$\theta$ range, ${ }^{\circ}$

$2.40-27.49$

113 Index ranges

$-12 \leq h \leq 16$

114

$-20 \leq k \leq 20$,

$-22 \leq l \leq 22$ 
116 No. of reflections collected

22656

117 Completeness to $\theta_{\max }$

$99.00 \%$

118 No. of independent reflections

7638

119 No. of observed reflections with $[I>2 \sigma(I)]$

6939

120 No. of refined parameters

410

121 Goodness of fit on $\left(F^{2}\right)$

0.967

$122 R 1(F)[I>2 \sigma(I)]$

0.0238

$123 w R 2(F 2)$ (all data)

0.0367

$124(\Delta / \sigma) \max$

0.001

125 Largest diffraction peak/hole, e/ $\AA^{3}$

$0.479 /-0.403$ 


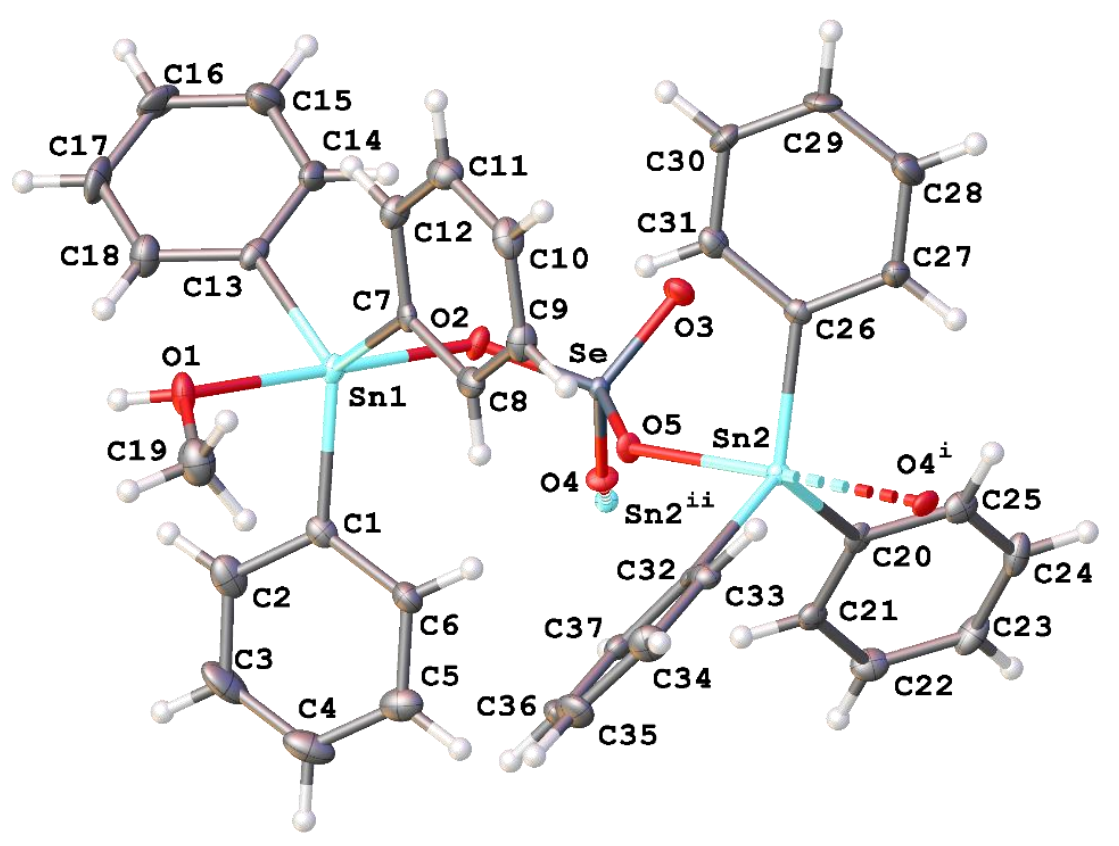

129 Figure 1. Crystal structure of $\mathbf{1}$ showing 50\% probability ellipsoids and the crystallographic 130 numbering scheme (OLEX2 view). Selected bond lengths and angles [A, $\left.{ }^{\circ}\right]$ : Sn1-O1 2.320(3), Sn1-O2 2.213(3), Sn1-C1 2.119(4), Sn1-C7 2.123(4), Sn1-C13 2.119(4), Sn2-O5 2.230(2), Sn2-O4 2.285(2), Sn2-C20 2.122(4), Sn2-C26 2.119(4), Sn2-C32 2.130(4), Se-O2 1.650(3), Se-O3 1.616(3), Se-O4 1.636(3), Se-O5 1.651(2), C19-O1 1.464(5); C13-Sn1-C7 134 117.07(16), C1-Sn1-C7 120.93(14), C1-Sn1-C13 121.54(14), C26-Sn2-C32 121.34(15), C26-Sn2-C20 119.84(15), C20-Sn2-C32 118.59(16), Se-O2-Sn1 139.91(14), Se-O5-Sn2 136 133.94(14), O4-Se-O5 107.04(13), O4-Se-O2 108.48(13), O2-Se-O5 107.71(13), 137 O3-Se-O5 110.65(12), O3-Se-O4 113.23(13), O3-Se-O2 109.55(14), C19-O1-Sn1 $138115.4(2),\left[\right.$ Symmetry operation: $\left.{ }^{\mathrm{i}}=1 / 2+\mathrm{x}, 1 / 2-\mathrm{y}, 1-\mathrm{z} ;{ }^{\mathrm{ii}}=-1 / 2+\mathrm{x}, 1 / 2-\mathrm{y}, 1-\mathrm{z}\right]$. 
139

140 Figure 2. The infinite chain of 1 propagating along the $a$-axis (MERCURY view) [Sn (light blue),

Se (yellow), O (red), C (grey)]. Hydrogen atoms and phenyl groups are omitted for clarity. omitted for clarity.

\section{Experimental}

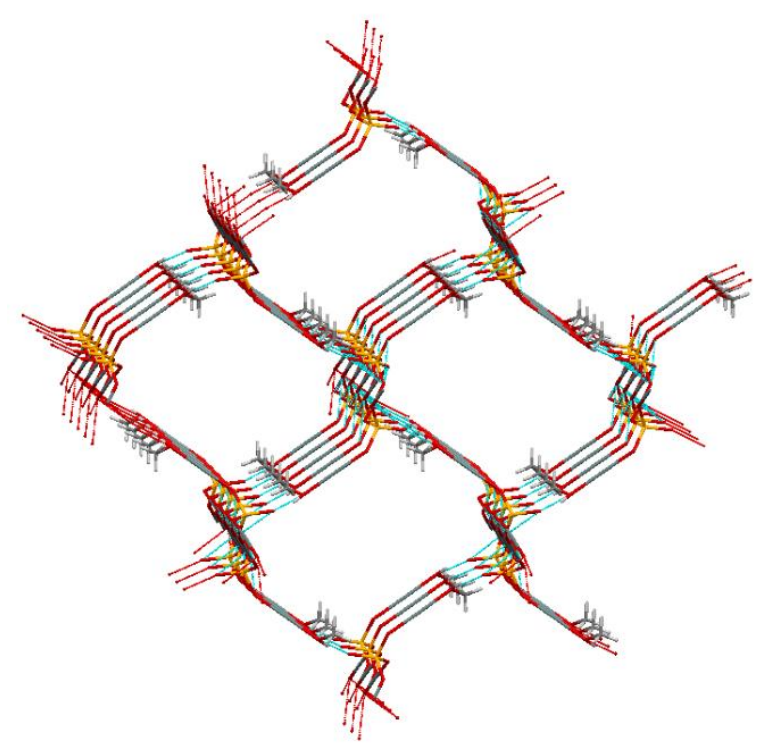

Figure 3. MERCURY view of the grid-shaped network resulting from the presence of intermolecular hydrogen bonds (blue dotted) between polymeric chains of $\mathbf{1}$. Phenyl groups are

\section{General}


$\left[\left(\mathrm{Ph}_{3} \mathrm{Sn}\right)_{2} \mathrm{SeO}_{4}\right] \cdot 1.5 \mathrm{H}_{2} \mathrm{O}$ was prepared according to a previously published procedure (Diop et al., 2007). Infrared spectra were recorded on a Bruker Vector 22 spectrometer (Wissenbourg, France) equipped with a Specac Golden Gate ${ }^{\mathrm{TM}}$ ATR device. ${ }^{1} \mathrm{H},{ }^{13} \mathrm{C}\left\{{ }^{1} \mathrm{H}\right\}$ and ${ }^{119} \mathrm{Sn}\left\{{ }^{1} \mathrm{H}\right\}$ spectra were recorded on a Bruker Avance 300 spectrometer in $\mathrm{CD}_{3} \mathrm{OD} .{ }^{1} \mathrm{H}$ and ${ }^{13} \mathrm{C}\left\{{ }^{1} \mathrm{H}\right\}$ chemical shifts $(\delta, \mathrm{ppm})$ were determined from the residual solvent signal $\left(\mathrm{CH}_{3} \mathrm{OH} \delta=3.31\right.$ and $\left.\mathrm{CH}_{3} \mathrm{OH} \delta=49.00\right) .{ }^{119} \mathrm{Sn}\left\{{ }^{1} \mathrm{H}\right\}$ chemical shifts $(\delta$, ppm) were reported downfield from $\left(\mathrm{CH}_{3}\right)_{4} \mathrm{Sn}$ used as external standard. Elemental analyses were performed at the "Plateforme d'Analyse Chimique et de Synthèse Moléculaire de l'Université de Bourgogne (PACSMUB)"' on a Fisons EA 1108 CHNS-O apparatus.

\section{Isolation of $\left[\left\{\left(\mathrm{Ph}_{3} \mathrm{Sn}\right)_{2} \mathrm{SeO}_{4}\right\} \cdot \mathrm{CH}_{3} \mathrm{OH}\right]_{n}(1)$}

An amount of $\left[\left(\mathrm{Ph}_{3} \mathrm{Sn}\right)_{2} \mathrm{SeO}_{4}\right] \cdot 1.5 \mathrm{H}_{2} \mathrm{O}(0.3 \mathrm{~g})$ was dissolved at room temperature in methanol (20 mL). Suitable colorless prism-shape crystals were obtained after few days of evaporation (37\% yield) and characterized by single-crystal X-ray diffraction as $\left[\left\{\left(\mathrm{Ph}_{3} \mathrm{Sn}\right)_{2} \mathrm{SeO}_{4}\right\} \cdot \mathrm{CH}_{3} \mathrm{OH}\right]_{n}$ (1). Compound $\mathbf{1}$ is relatively stable over time and in ambient air (no significant degradation observed), which facilitated its handling and characterization.

${ }^{1} \mathrm{H}-\mathrm{NMR}(\mathrm{ppm}): \delta=7.75\left[\mathrm{br}, 12 \mathrm{H}\right.$, phenyl protons, $\left.J\left({ }^{117,119} \mathrm{Sn}-\mathrm{H}\right)=63 \mathrm{~Hz}\right] ; \delta=7.42[\mathrm{br}, 18 \mathrm{H}$, phenyl protons], $\delta=3.34\left[\mathrm{~s}, 3 \mathrm{H}, \mathrm{CH} H_{3} \mathrm{OH}\right] .{ }^{13} \mathrm{C}\left\{{ }^{1} \mathrm{H}\right\}-\mathrm{NMR}(\mathrm{ppm}): \delta=137.6, \mathrm{C}(\mathrm{o})$ $\left[J\left({ }^{117,119} \mathrm{Sn}-\mathrm{C}\right)=46 \mathrm{~Hz}\right] ; \delta=130.9, \mathrm{C}(\mathrm{p}), \delta=129.9, \mathrm{C}(\mathrm{m})\left[J\left({ }^{117,119} \mathrm{Sn}-\mathrm{C}\right)=70 \mathrm{~Hz}\right] .{ }^{119} \mathrm{Sn}\left\{{ }^{1} \mathrm{H}\right\}-$ NMR (ppm): -193.6; -215.1. IR (ATR, $\left.\mathrm{cm}^{-1}\right)$ : 3046 (w), 1622 (w), 1578 (w), 1480 (w), 1430 (m), 1075 (w), 1023 (w), 998 (w), 818 (s), 727 (s), 693 (s). Anal. Calc. for $\mathrm{C}_{37} \mathrm{H}_{34} \mathrm{O}_{5} \mathrm{SeSn}_{2}$ (804.04 g. $\mathrm{mol}^{-1}$ ): Calc: C 50.79, H 3.92. Found: C 50.49, H 4.00.

\section{X-ray crystallography}

A suitable crystal of $\mathbf{1}$ was selected and mounted on a mylar loop with oil. Crystallographic 
175 data collection was recorded with a Bruker Kappa Apex II diffractometer. The crystal $(0.33 \times$

$1760.25 \times 0.12 \mathrm{~mm}^{3}$ ) was kept at $T=115 \mathrm{~K}$ during data collection. Using OLEX2 (Dolomanov et

177 al., 2009), the structure was solved with the XT (Sheldrick, 2015) structure solution program,

178 using the Intrinsic Phasing solution method. The model was refined with version 2014/7 of XL

179 (Sheldrick, 2008) using Least Squares minimisation. All non-hydrogen atoms were refined

180 anisotropically. Hydrogen atom positions were calculated geometrically and refined using the

181 riding model. Programs used for the representation of the molecular and crystal structures:

OLEX2 (Dolomanov et al., 2009), and MERCURY (Macrae et al., 2008).

Crystallographic data for the structural analysis has been deposited with the Cambridge

Crystallographic Data Centre, CCDC numbers 2080826. Copies of this information may be obtained free of charge from The Director, CCDC, 12 Union Road, Cambridge CB2 1EZ, UK (Fax: +44-1223-336033; e-mail: deposit@ccdc. cam.ac.uk or http://www.ccdc.cam.ac.uk).

Research funding: This work was supported by the Cheikh Anta Diop University of Dakar (Senegal), the Centre National de la Recherche Scientifique (CNRS, France) and the University of Bourgogne Franche-Comté (Dijon, France).

192

Author contributions: Waly Diallo: conceptualization, investigation, writing - original draft;

Hélène Cattey: investigation - crystal analysis, review; Laurent Plasseraud: supervision, writing - review and editing.

Conflict of interest: Authors state no conflict of interest.

\section{References}


Baran J., Barnes A.J., Marchewka M.K., Pietraszko A., Ratajczak H., Structure and vibrational spectra of the bis(betaine)-selenic acid molecular crystal. J. Mol. Struct. 1997, 416, 33-42.

Ben Hassen C., Boujelbene M., Bahri M., Zouari N., Mhiri T., Experimental study on the structure and vibrational, thermal and dielectric properties of bis(2-methylanilinium) selenate accomplished with DFT calculation. J. Mol. Struct. 2014, 1074, 602-608.

Diallo W., Diop, C.A.K., Diop L., Mahon M.F., Molloy, K.C., Russo U., Biesemans M., Willem R. Molecular structures of $\left[\left(\mathrm{Ph}_{3} \mathrm{Sn}\right)_{2} \mathrm{O}_{3} \mathrm{Se}\right]$ and $\left[\left(\mathrm{Ph}_{3} \mathrm{Sn}\right)_{2} \mathrm{O}_{4} \mathrm{Cr}\right]\left(\mathrm{CH}_{3} \mathrm{OH}\right)$. J. Organomet. Chem. 2007, 692, 2187-2192.

Diallo W., Diop L., Diop C.A.K., Cattey H., Plasseraud L., Synthesis, spectroscopic study, and crystal structure of a new organotin(IV) selenate derivative, Main Group Met. Chem. 2018, 41, 183-188.

Diop C.A.K., Toure A., Diop A., Bassene S., Sidibe M., Diop L., Mahon M.F., Molloy K.C., Russo U., Synthesis, infrared, Mössbauer, NMR spectroscopic characterization and X-ray structure of $\left[\left(\mathrm{Ph}_{3} \mathrm{Sn}\right)_{2} \mathrm{O}_{4} \mathrm{Se}\right] \cdot 1.5 \mathrm{H}_{2} \mathrm{O},\left[\left(\mathrm{Me}_{3} \mathrm{Sn}\right)_{2} \mathrm{O}_{4} \mathrm{Se}\right]\left(\mathrm{OH}_{2}\right)_{2}$ and $\left[\mathrm{Me}_{3} \mathrm{SnO}_{2} \mathrm{AsMe}_{2}\right] \cdot 0.5 \mathrm{H}_{2} \mathrm{O}$. J. Soc. Ouest-Afr. Chim. 2007, 12, 49-59.

Dolomanov O.V., Bourhis L.J., Gildea R.J., Howard J.A.K., Puschmann H., OLEX2: a complete structure solution, refinement and analysis program. J. Appl. Crystallogr. 2009, 42, 339-341.

Holeček J., Nádvorník M., Handlíř K., Lyčka A., ${ }^{13} \mathrm{C}$ and ${ }^{119} \mathrm{Sn}$ NMR study of some four- and five-coordinate triphenyltin(IV) compounds. J. Organomet. Chem. 1983, 241, 177-184.

Macrae C.F., Bruno I.J., Chisholm J.A., Edgington P.R., McCabe P., Pidcock E., RodriguezMonge L., Taylor R., van der Streek J., Wood P.A., MERCURY CSD 2.0 - new features for the visualization and investigation of crystal structures. J. Appl. Cryst. 2008, 41, 466-470.

Parvez M., Bhatti M.H., Ali S., Mazhar M., Qureshi S.I., (N-Maleoylglycinato)trimethyltin(IV). Acta Crystallogr. 2000, C56, 327-328. 
225 Plasseraud L., Organotin(IV) complexes containing Sn-O-Se moieties: a structural inventory. 226 Synthesis 2018, 50, 3653-3661.

227 Sheldrick G.M., A short history of SHELX. Acta Crystallogr. 2008, A64, 112-122.

228 Sheldrick G.M., SHELXT - Integrated space-group and crystal-structure determination, Acta $229 \quad$ Crystallogr. 2015, A71, 3-8.

230 Soukrata S., Belhouchet M., Suñol J.J., Mhiri T. Synthesis, Crystal Structure, and 231 Characterization of A New Adduct Bis-(2-Amino-3-Benzyloxypyridinium) Selenate 232 Monohydrate $\left[\mathrm{C}_{12} \mathrm{H}_{13} \mathrm{~N}_{2} \mathrm{O}\right]_{2} \mathrm{SeO}_{4} \cdot \mathrm{H}_{2} \mathrm{O}$. Phosphorus, Sulfur Silicon Relat. Elem. 2014, 189, 233 $422-431$. 